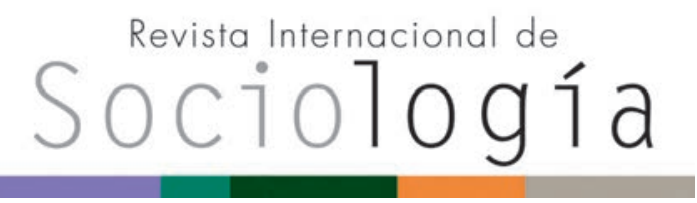

Revista Internacional de Sociología RIS

vol. 75 (4), e075, octubre-diciembre, 2017, ISSN-L:0034-9712

doi: http://dx.doi.org/10.3989/ris.2017.75.4.17.02

\section{LAS DIMENSIONES SOCIALES DE LA PERCEPCIÓN DE LA ENERGÍA NUCLEAR. Un análisis del caso español (1960-2015)}

Josep Espluga TRENC

Universidad Autónoma de Barcelona, España

joseplluis.espluga@uab.cat

ORCID iD: http://orcid.org/0000-0002-5058-2411

Beatriz Medina

Universidad Autónoma de Barcelona, España

beatriz.medina@uab.cat

ORCID iD: http://orcid.org/0000-0002-7136-304X

Albert Presas

Universidad Pompeu Fabra, España

albert.presas@upf.edu

ORCID iD: http://orcid.org/0000-0003-0723-7185

MAR RUBIO-VARAS

Universidad Pública de Navarra, España

mar.rubio@unavarra.es

ORCID iD: http://orcid.org/0000-0002-8100-2651

Joseba De La ToRre

Universidad Pública de Navarra, España

jdelatorre@unavarra.es

ORCID iD: http://orcid.org/0000-0002-5235-7429

Cómo citar este artículo / Citation: Espluga Trenc, J., B. Medina, A. Presas, M. Rubio-Varas y J. De la Torre. (2017).

"Las dimensiones sociales de la percepción de la energía nuclear. Un análisis del caso español (1960-2015)". Revista Internacional de Sociología 75 (4): e075. doi: http://dx.doi. org/10.3989/ris.2017.75.4.17.02

\section{THE SOCIAL DIMENSIONS OF THE PERCEPTION OF NUCLEAR ENERGY. \\ An analysis of the Spanish case (1960-2015)}

Copyright: (C) 2017 CSIC. Este es un artículo de acceso abierto distribuido bajo los términos de la licencia Creative Commons Attribution (CC BY) España 3.0.

Recibido: 15/12/2016. Aceptado: 10/07/2017. 


\section{Resumen}

La energía nuclear es una tecnología compleja, que requiere un uso muy intensivo de recursos y una toma de decisiones muy centralizada, cuya gobernanza supone un auténtico reto para las sociedades democráticas. En el presente artículo se exploran las percepciones sociales sobre la energía nuclear en España a partir de un análisis de encuestas de opinión y de los argumentos de actores de tres estudios de caso (Vandellós I, Valdecaballeros y ATC). Los resultados muestran cómo las argumentaciones de unos y otros actores se basan en diferentes dimensiones del riesgo, a menudo ignoradas en las encuestas y por varios de los actores, lo cual supone una seria dificultad para superar las controversias suscitadas por este tipo de energía.

\section{Palabras Clave}

Conflictos energéticos; Conflictos socioambientales; Historia nuclear; Percepción del riesgo; Políticas del riesgo.

\section{INTRODUCCIÓN}

La producción, distribución y consumo de energía son actividades con un importante rango de impactos sociales que, de alguna manera, nos ayudan a entender cómo son nuestras sociedades (Prades 1997). La energía nuclear constituye un tipo particularmente interesante de fuente e infraestructura energética, hasta el punto de que las protestas que se han generado a su alrededor han conformado buena parte de los movimientos ecologistas contemporáneos, mientras que las controversias políticas y científicas que genera han contribuido a dar forma a las instituciones de la segunda mitad del siglo XX (Riechmann y Fernández Buey 1994; Dobson 1997). Dada la enorme complejidad técnica de su diseño y gestión, sus orígenes militares, la gran concentración de capital necesaria para hacerla operativa, sus riesgos para la salud y el medio ambiente, la energía nuclear resulta una tecnología controvertida y su gobernanza supone un auténtico reto para las sociedades democráticas.

En el presente texto pretendemos analizar las percepciones de varios actores sociales ante la energía nuclear en España, con la finalidad de entender cuál es el núcleo argumentativo en disputa sobre esta fuente energética. Para ello utilizaremos un marco integrado de teorías de percepción social del riesgo. Nuestro punto de partida se basa en la idea de que diferentes actores (promotores, reguladores, movimientos sociales, etc.) interpretan de manera diferente los riesgos de la energía nuclear, y por tanto realizan propuestas dispares y no siempre congruentes. ¿En qué sentido la energía nuclear es considerada un riesgo por los diferentes actores sociales? EI concepto de riesgo remite a la posibilidad de que se produzcan daños o pérdidas. Desde una racionalidad tecnocientífica dicha posibilidad se puede intentar cuantificar en términos probabilísticos. Es lo que

\section{Abstract}

Nuclear energy is a complex technology that requires intensive use of resources and high centralized decision-making processes, whose governance poses a real challenge for democratic societies. In this article we explore the social perceptions about nuclear energy in Spain through the analysis of opinion surveys and secondary data about the main actors of three case studies (Vandellós I, Valdecaballeros, and Radioactive Waste Storage). The results show how the arguments of the several actors are based on very different dimensions of risk, often ignored in the surveys and by the actors, which represents a serious difficulty to overcome the controversies caused by this type of energy.

\section{KEYWORDS}

Energy conflicts; Nuclear history; Risk perception; Risk policies; Socioenvironmental conflicts.

hacen los expertos en análisis de riesgo cada vez que se produce un nuevo accidente nuclear: recalculan las probabilidades de ocurrencia de daños y la posible magnitud de estos, de acuerdo con sofisticadas metodologías de análisis de riesgos. Pero, aunque nos podamos poner de acuerdo en la estimación de probabilidades de que se produzcan daños o pérdidas, no resulta tan fácil consensuar qué tipo de daños o pérdidas son los más relevantes. Aquí radica el núcleo del problema que pretendemos explorar en este artículo.

La bibliografía sobre el tema muestra que la aceptación u oposición pública ante la energía nuclear se explica por una combinación de numerosos factores que dan forma a las percepciones y valores de los individuos, tales como la confianza en las instituciones, la existencia de procedimientos justos y transparentes, la tolerabilidad al riesgo, la disponibilidad de información científica, el rol percibido de la energía nuclear en la mitigación del cambio climático antropogénico, etc. (Poortinga et al. 2006; Pidgeon et al. 2008; Parkhill et al. 2010; Besley 2012; Visschers y Siegrist 2012). Estos factores van más allá de las simples interacciones directas con la industria nuclear o con los gobiernos, y reflejan un espectro de interacciones en el seno de las comunidades locales y de la sociedad en sentido más amplio (Lemkow 1984; Slovic 1996; Prades et al. 2015; Whitton et al. 2016). Dichos complejos factores se pueden rastrear en las principales corrientes teóricas sobre el riesgo, como el paradigma psicométrico, la teoría cultural del riesgo, las aproximaciones interpretativas al riesgo o las teorías de la gobernanza de riesgos. Todos estos factores pueden ser agrupados en un marco analítico que consta de cuatro dimensiones generales, que señalan los diferentes tipos de daños o pérdidas que los individuos pueden percibir en su exposición a un riesgo, y que se pueden definir de la siguiente manera: 
a) Dimensiones de salud y medio ambiente: Esta dimensión incluye las percepciones de efectos positivos y/o negativos relacionados con la salud humana (efectos agudos o crónicos) y con aspectos ambientales (como contaminación de agua, suelo o atmósfera, pérdida de biodiversidad, efectos sobre el cambio climático global, etc.), así como preocupaciones por la gestión de medidas para evitar dichos efectos (medidas de seguridad, etc.).

b) Dimensiones económicas: Esta dimensión se refiere a la percepción de factores relacionados con aspectos económicos, tanto positivos como negativos. Temas como la potencial (o real) creación de empleo, el florecimiento de nuevos negocios relacionados con el diseño, construcción o gestión de infraestructuras nucleares, posibles pérdidas económicas debidas a incidentes nucleares, mayor o menor garantía de suministro eléctrico, monto de inversiones económicas requeridas (públicas o privadas) que se detraen de otras áreas, preocupaciones por el precio de la energía, etc.

c) Dimensiones socioculturales: Estas dimensiones se refieren a varios factores identificados principalmente por dos de las corrientes principales en el análisis de riesgos desde una vertiente social: el paradigma psicométrico y la teoría cultural del riesgo. El paradigma psicométrico parte del supuesto de que, contrariamente a lo esperado, no siempre hay una correlación entre la percepción de beneficios generados por una actividad o tecnología y la percepción de riesgo a la que da lugar (Otway y Cohen 1975; Slovic 1987). En este sentido, se ha constatado que ciertos factores pueden influir en las respuestas individuales al riesgo, como la voluntariedad en la exposición al mismo, la familiaridad con el riesgo, la controlabilidad de las consecuencias, la aparición diferida de las consecuencias en el tiempo o el espacio, etc. (Fischhoff et al. 1978; Vlek y Stallen 1980; Slovic 1993). Además, la investigación en percepción de riesgos mostró cómo diferentes grupos sociales pueden desarrollar diferentes percepciones de riesgo en función de su adhesión a ciertos valores sociales, creencias o estándares culturales (Otway y Fischbein 1976; Otway y Von Winterfeldt 1982, 1992). Desde la teoría cultural del riesgo se explica cómo las preocupaciones o temores ante un riesgo pueden contribuir (intencionadamente o no) a la cohesión de un grupo social determinado, generando un cierto grado de identidad social, por lo que el riesgo puede jugar un rol en el mantenimiento de un cierto orden social (Douglas y Wildavsky 1982). Ello explicaría que ciertos grupos privilegian la percepción de ciertos riesgos sobre otros. En esta dimensión socio-cultural entrarían impactos como la percepción de amenazas a redes de relaciones sociales, a identidades sociales o territoriales, a cier- tos estilos de vida, tradiciones culturales, valores y creencias, etc.

d) Dimensiones politicoinstitucionales: Para entender las respuestas sociales ante un riesgo no basta con conocer las percepciones de la población, sino que es preciso analizar el contexto de relaciones sociales en el que dichas respuestas tienen lugar, considerando aspectos como la credibilidad de las entidades o instituciones que lo gestionan, la confianza que merecen, la percepción de justicia o injusticia en sus actos, la percepción de equidad o inequidad, el tomar en cuenta el bien común, cuestiones de gobernanza, etc., y toda la serie de dimensiones institucionales que forman parte del proceso de interacción con el riesgo (Turner y Wynne 1992; Renn 2008). Desde esta perspectiva, no es fácil separar las percepciones de riesgo del contexto social, económico o político en el que se producen (Walker et al. 1998; Irwin et al. 1999; Van Loon 2000). Así, el hecho de que una población no proteste contra un riesgo no implica necesariamente que lo acepte sin más, sino que puede que sus relaciones de dependencia (social, psicológica, económica, política) con las instituciones involucradas en la promoción y/o gestión del riesgo les impida hacer visible su rechazo (Wynne 1996). Por tanto, es necesario considerar que cuando una persona emite un juicio sobre un riesgo, implícitamente está haciendo también una evaluación sobre las instituciones que lo promueven y gestionan, y emitiendo un juicio sobre la credibilidad o confianza que le merecen.

Consideramos de máxima importancia tener en cuenta estas diferentes posibilidades (dimensiones) a la hora de interpretar las percepciones de riesgo de los actores relacionados con la energía nuclear. Se pretende así huir de la distinción simplista entre actores favorables y contrarios a la energía nuclear, que es como se suelen caracterizar este tipo de conflictos socioambientales. En cambio, esta perspectiva nos permitirá explicar mejor las frecuentes ambivalencias que caracterizan los procesos de negociación del riesgo; pues un actor puede estar de acuerdo en que la energía nuclear supone un beneficio económico, por ejemplo, y, al mismo tiempo, considerar inasumibles los riesgos que percibe hacia ciertas identidades locales, usos del territorio, y/o considerar insoportable la pérdida de confianza en instituciones públicas o privadas encargadas de gestionarlo (Espluga et al. 2014). Ello tendrá consecuencias en las estrategias utilizadas para gestionar los conflictos relacionados con la energía nuclear, pues es obvio que de nada servirá ofrecer más o mejor información sobre una dimensión (por ejemplo, sobre los riesgos ambientales o para la salud, o sobre beneficios económicos) si el motivo de fondo del conflicto se sitúa en otras de las dimensiones mencionadas. 
A continuación se contextualiza la evolución de la energía nuclear en España, se describen las encuestas de opinión que se han llevado a cabo y se analizan tres casos o eventos concretos con la finalidad de explorar las argumentaciones de los diferentes actores. La metodología utilizada ha sido el análisis documental (prensa, webs, informes, libros, etc.) de los casos de estudio escogidos (ver apartado específico en cada caso).

El análisis realizado no tiene pretensión de ser una investigación exhaustiva ni sistemática, sino más bien un estudio exploratorio cuya finalidad primordial es ilustrar el funcionamiento del marco teórico propuesto para dar cuenta de las dimensiones sociales del riesgo.

\section{EvoluCIÓN DE LA ENERGía NUCLEAR EN ESPAÑA}

En España la investigación en materia nuclear se inició oficialmente en 1948 con la creación del organismo de Estudios y Patentes de Aleaciones Especiales (EPALE), poco después rebautizado como Junta de Energía Nuclear, una agencia gubernamental creada en 1951 que inicialmente estaba bajo el control directo del Gobierno. Durante los años 60 se elaboró un Plan energético basado fundamentalmente en la energía nuclear; de tal modo que, a mediados de los 70, España era ya el principal cliente internacional de las principales empresas proveedoras de este tipo de infraestructuras (sobre todo estadounidenses), con un programa nuclear oficial que ya había pre-autorizado más de 20 reactores y con planes de construir unos 40 (Fundación Encuentro 2009; De la Torre y Rubio-Varas 2015, 2016). A pesar de que a mediados de los años 50 del pasado siglo España era un país poco desarrollado y gobernado por una dictadura, una serie de circunstancias históricas lo situó en el grupo de países pioneros en la adopción de la energía nuclear civil. El fuerte apoyo del Estado a los inversores privados que controlaban el mercado eléctrico en régimen de oligopolio, la importante transferencia tecnológica y financiera de Estados Unidos, principalmente, pero también de Francia y Alemania, convirtieron a España en uno de los países más nuclearizados de la época (RubioVaras y De la Torre 2016). El primer reactor nuclear (Zorita) se conectó a la red en 1968.

Durante los años 50 y 60, los promotores (privados y estatales) presentaron la energía nuclear como la única alternativa plausible para satisfacer las supuestas futuras necesidades de electricidad. Encontraron poca resistencia porque, además del marco tecnoentusiasta en el que se desarrollaba dicha tecnología, existía muy poco conocimiento entre la población. Por ello los primeros proyectos nucleares apenas tuvieron oposición pública, de tal forma que a principios de los años setenta España se convirtió en el país donde la energía nuclear creció más rápido en el mundo occidental, con planes para la construcción de más de cuarenta reactores y casi una veintena de contratos formalizados para su construcción inminente. Sin embargo, a principios de los 70 se empezaron a oír voces críticas, sobre todo a nivel local; de modo que varios ayuntamientos consiguieron paralizar proyectos nucleares vía alegaciones y recursos administrativos. La dictadura prohibió el activismo civil pero, sin embargo, grupos antinucleares informales y todavía poco estructurados se fueron desarrollando a lo largo de los años 70 alrededor de unos activistas locales cada vez más organizados, que pronto aprendieron a funcionar en red y con contactos internacionales (Costa Morata 1976, 2009; Fernández 1999). La coincidencia con el final de la dictadura convirtió estas redes en parte constituyente del abanico de grupos de oposición al franquismo, lo cual sumó argumentos extratecnológicos al rechazo nuclear (Rubio-Varas y De la Torre 2016).

Más allá de las voces sociales críticas a nivel local y regional, el ciclo económico y político desempeñó un papel crucial para frenar y posteriormente paralizar el programa nuclear español. Las dos crisis petroleras (1974 y 1979) ralentizaron la economía y las necesidades de electricidad esperadas, contribuyendo así a que la carga financiera de los proyectos nucleares fuera difícilmente asumible para las empresas privadas y para los organismos públicos implicados. A ello se sumaron las incertidumbres del momento histórico en España ocasionadas por la transición a la democracia (1975-1982), caracterizada por una inestabilidad institucional agravada por amenazas de golpe militar y por una creciente expansión de acciones terroristas -que en Euskadi incluyeron a la energía nuclear entre sus objetivos icónicos- (Bárcena 1995). El Gobierno salido de las elecciones de octubre de 1982 (PSOE) se encontró con una enorme oposición pública al programa nuclear y con una situación económica insostenible en sus proyectos, por lo que en 1983 se proclamó una moratoria nuclear, vigente a partir de 1984, y de la que las empresas privadas promotoras obtuvieron la correspondiente compensación por el lucro cesante (que se incluyó como una tasa en la factura eléctrica y se acabó de pagar en diciembre de 2015). De este modo, a finales de la década de 1980 solo 10 reactores nucleares producían electricidad, con todos los planes restantes abandonados o sujetos a la moratoria nuclear. En 2016 todavía permanecen 7 reactores en activo que aportan al sistema eléctrico un $20 \%$ de la energía total (Rubio-Varas et al. 2017). Mediante todo este proceso, la población española de la época democrática se convirtió en una de las más reticentes a la energía nuclear en Europa, con una oposición pública latente reconocida por todos los actores, ocasionalmente explícita por ciertos desencadenantes como accidentes e incidentes, ampliación de licencias nucleares o ubicación de almacenamiento de residuos. 


\section{Percepción pública de la energía NUCLEAR SEGÚN LAS ENCUESTAS DE OPINIÓN}

Las encuestas de opinión pueden aportar indicios sobre las actitudes del público hacia la energía nuclear y sus cambios (si los hay) a través del tiempo, tanto a nivel nacional como local. En este apartado se presenta una visión general de las pruebas disponibles en los sondeos de opinión sobre cuestiones relacionadas con la energía nuclear en España. Se observa que, aunque en España se han realizado bastantes encuestas de opinión pública (a nivel nacional y local), hay poca consistencia entre ellas en términos de diseño, de objetivos específicos y de muestreo, lo cual limita mucho las posibilidades de hacer comparaciones históricas fiables. La Figura 1 muestra el número de encuestas de opinión pública sobre temas nucleares identificados (se han excluido otras encuestas sobre otros temas que incluyen alguna pregunta aislada sobre actitudes ante la energía nuclear).

Varios factores pueden ayudar a entender la evolución de esta serie de encuestas:

- 1975-1977: El Fórum Nuclear español (la patronal del sector) crea un grupo de trabajo sobre opinión pública, y el Ministerio de Industria y la Junta de Energía Nuclear llevaron a cabo dos encuestas para recoger información sobre opinión pública. La primera fue realizada en 1974, mientras que en 1977 se hicieron solo en tres poblaciones afectadas por el plan nuclear: Cofrentes, Garoña y Regodela.

- 1978: Se lleva a cabo la primera encuesta realizada a una muestra representativa de la población española en su conjunto (Centro de Investigaciones Sociológicas 1978). Sus objetivos fueron conocer el nivel de información sobre energía, y en particular sobre energía nuclear, que tenía la población.

- 1987: Se realizaron varias series de encuestas de opinión justo después del accidente de
Chernóbil (1986). Sus impulsores fueron entidades como el Consejo de Seguridad Nuclear (organismo regulador del sector), a través de la empresa Emopública. A nivel europeo varias encuestas del Eurobarómetro trataron también el tema. El organismo especializado en encuestas en España, el Centro de Investigaciones Sociológicas (CIS), no incluyó este tema en sus series regulares a nivel nacional hasta 1990.

- 1990: Se realizaron varios estudios de opinión con posterioridad al accidente de la central Vandellós I, en años sucesivos (1991, 1992, 1993), combinados también con el Eurobarómetro.

- A partir de 1996, coincidiendo con el décimo aniversario del accidente de Chernóbil, se realizaron tres encuestas de ámbito europeo (Eurobarómetro) y español (CIS).

- En 2007, con la aprobación del VI Plan General de Residuos Radioactivos, se llevaron a cabo varias encuestas principalmente centradas en las percepciones y conocimientos de la población sobre los residuos radioactivos.

- En 2011, a raíz del accidente nuclear de Fukushima-Daiichi (Japón), el barómetro del CIS del mes de mayo incluyó varias preguntas de opinión sobre energía nuclear.

Como se ha mencionado, los datos demoscópicos disponibles son muy fragmentados y dispersos (en términos de contenidos, muestras, etc.), por lo que las comparaciones y análisis longitudinales son necesariamente muy indiciarios. Se observa, por ejemplo, que la población española fue preguntada por primera vez sobre sus actitudes hacia la energía nuclear en 1975, aún durante la dictadura franquista, y lo más reseñable de los resultados de dicha encuesta es que la mayoría (un $45 \%$ ) expresaba su indiferencia hacia esta fuente energética en aquellos momentos. Un $20 \%$ de la población encuestada se posicionaba a favor y un $35 \%$ en contra (Solà Farré

\section{Figura 1}

Número de encuestas de opinión de ámbito estatal realizadas en España

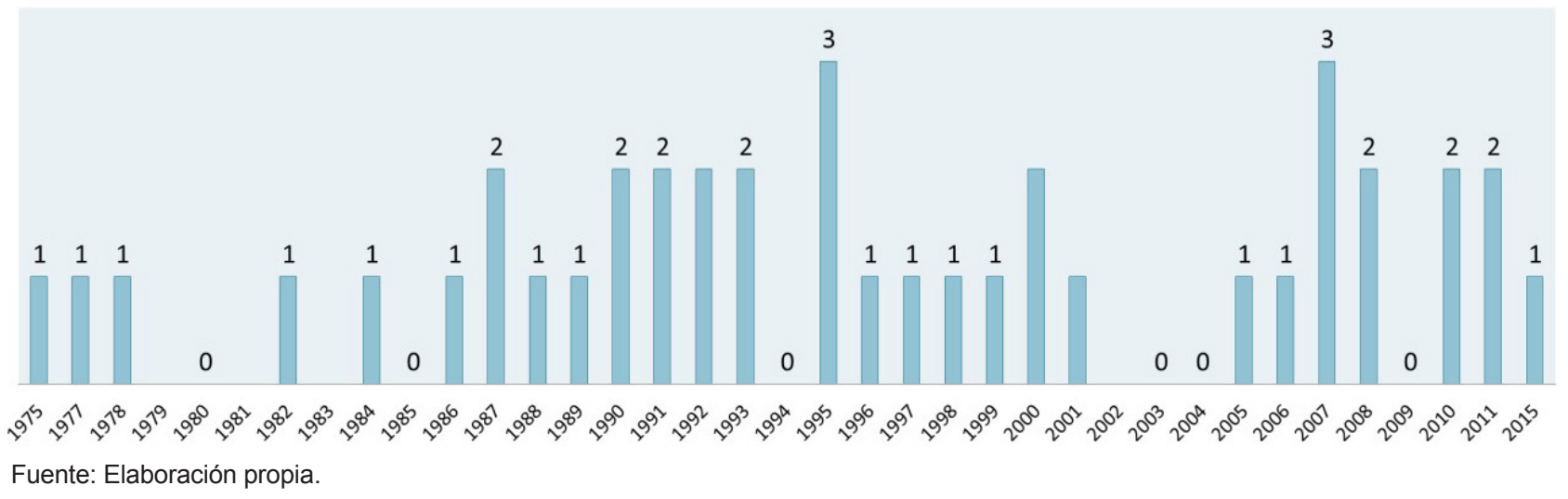


1999). Unos años después, en 1988 (la primera tras el accidente de Chernóbil), se observa que la falta de conocimiento sobre la energía nuclear continuaba siendo notable, con más de un $35 \%$ de la muestra diciendo que no sabe qué es, mientras que solo el $17 \%$ consideraba aceptables los riesgos nucleares. Chernóbil se identificaba como la peor catástrofe nuclear, y vivir en las cercanías de una central nuclear o trabajar en una mina de uranio se consideraban las actividades más peligrosas, y casi la mitad de la población española (47 \%) percibía los riesgos nucleares como inaceptables (en Europa el porcentaje era del $51 \%)$.

De hecho, esto se corresponde con las escasas evidencias longitudinales (basadas en datos de Eurobarómetros y del CIS, cubriendo desde los años 90 hasta hoy día), que muestran que una mayoría de personas (alrededor del $60 \%$ ) se muestra contraria a la energía nuclear (Baigorri et al. 2015, realizan un interesante y exhaustivo análisis de los datos de la evolución del Eurobarómetro y del CIS). Uno de los últimos eurobarómetros sobre el tema (2010) permite comparar la situación de España en el contexto europeo (aunque hay que advertir que la toma de datos se hizo antes del accidente de Fukushima, de marzo de 2011), y se observa que España es uno de los países con mayor oposición pública a la energía nuclear: un $73 \%$ de las personas que respondieron a la encuesta afirmaron considerar la presencia de centrales nucleares como un riesgo importante para ellas y sus familias, siendo la media de la UE-27 del $52 \%$ para esta misma cuestión. Más recientemente, en 2015, una encuesta encargada por el Foro Nuclear Español mostraba que el $60 \%$ de la población española se declaraba contraria a las centrales nucleares (FNE 2015), confirmando a grandes rasgos las tendencias de las últimas tres décadas.

Muchas de las encuestas realizadas han intentado indagar cuáles son los riesgos y beneficios que la gente percibe ante la energía nuclear. Un análisis de las preguntas formuladas en los cuestionarios muestra que las dimensiones de riesgo sobre las que se suele preguntar son principalmente de dos tipos: i) riesgos para la salud (accidentes y enfermedades relacionadas con la radiación) y para el medio ambiente (contaminación del aire, aguas, suelos, alimentos, pérdida de biodiversidad, etc.), o beneficios en dichos ámbitos (mitigación del cambio climático, etc.); y ii) riesgos económicos (precio de la energía, garantía de suministro, costes, etc.) o beneficios en este ámbito (generación de empleo, riqueza, etc.). Otras dimensiones que aparecen en menor medida tienen que ver con la percepción de vínculos militares y con la dependencia energética de otros países. En la tabla 1 se detallan, a modo de ejemplo, las dimensiones que aparecen en las encuestas de 1978 y de 1990, que no han variado demasiado en series posteriores.
En la encuesta más reciente de las aquí consultadas, la promovida por el Foro Nuclear en 2015, se mencionan también varios argumentos a favor y en contra de la energía nuclear, que se centran sobre todo en la dimensión económica y los efectos ambientales, tanto en sentido positivo como negativo. En concreto, se pregunta si:

- Es una tecnología no emisora de gases efecto invernadero (GEI) (aunque el $15 \%$ destaca que no emite $\mathrm{GEl}$, un $22 \%$ mencionan la contaminación "radiactiva" y los "residuos radiactivos" como efecto desfavorable).

- Las centrales nucleares garantizan el suministro eléctrico y reducen la dependencia exterior (aunque solo el $5 \%$ de los consultados destacan este aporte y garantía como ventaja o beneficio de la energía nuclear, y solo el $4 \%$ mencionan la independencia respecto a otros países).

- El coste económico de la producción nuclear de electricidad (aunque el $31 \%$ de los consultados destaca como beneficio de la nuclear su coste de producción, el $5 \%$ destacan que, si se incluyen todos los costes o si se incluye la inversión inicial, el control de producción, la gestión de residuos o el desmantelamiento, no es más económica que otras fuentes).

En el Barómetro del CIS de 2011 se pedía a las personas encuestadas que eligieran con cuales de las siguientes opiniones estaban más de acuerdo:

- "Los riesgos de la energía nuclear, como fuente de energía, superan los beneficios".

- "Los beneficios de la energía nuclear, como fuente de energía, superan los riesgos".

El $52 \%$ de las personas encuestadas se acogieron a la primera opción y el $32 \%$ a la segunda (el 16 $\%$ restante NS/NC). De acuerdo con nuestra tesis, una pregunta de este tipo es necesariamente confusa porque la posible respuesta está conformada por varias dimensiones que previamente convendría dilucidar y tratar por separado para poder interpretarla correctamente. De hecho, la dicotomía que se propone entre riesgos y beneficios puede que no siempre se dé en la realidad, pues nada impide que la energía nuclear pueda suponer riesgos altos y beneficios altos (o bajos) a la vez, una respuesta que no encontraría acomodo en el cuestionario así redactado.

\section{LA PERCEPCIÓN DEL RIESGO NUCLEAR A PARTIR DE CASOS CONCRETOS}

Las encuestas de opinión nos ofrecen una información relativamente superficial y difícil de interpretar, pues tras esos amplios porcentajes se encuentran agregadas respuestas potencialmente muy dispares. ¿En qué sentido la energía nuclear se considera un riesgo o un beneficio? Para intentar responder a 
Tabla 1

Preguntas y opciones de respuesta establecidas en las encuestas de 1978 y de 1990, que indican cómo se conciben los riesgos y beneficios de la energía nuclear

\begin{tabular}{|c|c|}
\hline Encuesta del CIS 1978 & Encuesta del CIS 1990 \\
\hline $\begin{array}{l}\text { ¿Cuál es la finalidad de la construcción de centrales } \\
\text { nucleares? } \\
\text { - Obtención de energía } \\
\text { - Energía más barata } \\
\text { - Resolver el problema futuro } \\
\text { - Investigación } \\
\text { - Fines militares } \\
\text { - Independencia energética } \\
\text { - Intereses económicos } \\
\text { - No sabe } \\
\text { - No contesta }\end{array}$ & $\begin{array}{l}\text { P. } 8 \text { “¿Piensa usted que la aplicación de energía nuclear puede } \\
\text { ser beneficiosa o perjudicial para su uso en los siguientes } \\
\text { campos?” } \\
\text { - Usos sanitarios } \\
\text { - Usos energéticos } \\
\text { - Usos industriales } \\
\text { - Usos militares }\end{array}$ \\
\hline $\begin{array}{l}\text { Principales peligros citados que ofrece una central nuclear } \\
\text { - Contaminación } \\
\text { - Radioactividad } \\
\text { - Peligro de explosiones e incendios } \\
\text { - Peligro de enfermedades y deformaciones } \\
\text { - Destrucción del medio ambiente } \\
\text { - Poca seguridad } \\
\text { - Otros }\end{array}$ & $\begin{array}{l}\text { P. } 23 \text { "Cree usted que la utilización de energía nuclear } \\
\text { proporciona alguna de las siguientes ventajas?" } \\
\text { - La energía nuclear resulta más barata que otras fuentes de } \\
\text { energía } \\
\text { - Utilizar energía nuclear ayuda a depender menos del petróleo } \\
\text { - La energía nuclear favorece el desarrollo tecnológico } \\
\text { - La utilización de energía nuclear ayuda a crear nuevos puestos } \\
\text { de trabajo } \\
\text { - La energía nuclear contamina menos la atmósfera que otras } \\
\text { fuentes de energía }\end{array}$ \\
\hline \multirow[t]{3}{*}{$\begin{array}{l}\text { La instalación de centrales nucleares, ¿aumenta la } \\
\text { dependencia del extranjero o forma parte del normal } \\
\text { intercambio comercial entre países? } \\
\text { - Aumenta la dependencia } \\
\text { - Intercambio comercial } \\
\text { - No sabe } \\
\text { - No contesta }\end{array}$} & $\begin{array}{l}\text { P. } 24 \text { "En su opinión, ¿la utilización de energía nuclear puede } \\
\text { suponer alguno de los siguientes inconvenientes?" } \\
\text { - Problemas para almacenar los residuos radioactivos } \\
\text { - Contaminación radioactiva } \\
\text { - Riesgo de accidentes } \\
\text { - Recalentamiento de los ríos }\end{array}$ \\
\hline & $\begin{array}{l}\text { P. } 27 \text { "¿Cree usted que el uso de energía nuclear puede tener } \\
\text { riesgos en la contaminación del aire? } \\
\text { P. } 28 \text { “Y del agua?" } \\
\text { P. } 29 \text { “YY de los alimentos?" }\end{array}$ \\
\hline & $\begin{array}{l}\text { P. } 30 \text { "De la siguiente relación de posibles riesgos que conlleva } \\
\text { la utilización de la energía nuclear, ¿podría usted señalar los } \\
\text { tres que considere tienen mayor posibilidad de ocurrir?" } \\
\text { - Recalentamiento de los ríos } \\
\text { - Contaminación radioactiva del entorno } \\
\text { - Accidente nuclear } \\
\text { - Contaminación radioactiva de las personas que trabajan con la } \\
\text { energía nuclear } \\
\text { - Accidentes en el transporte de residuos radioactivos } \\
\text { - Riesgo de contaminación a través de los residuos radiaoctivos } \\
\text { - } \quad \text { Aumento de enfermedades provocadas por la radioactividad } \\
\text { - NS/NC }\end{array}$ \\
\hline
\end{tabular}

Fuente: Elaboración propia a partir de las respectivas encuestas.

esta pregunta y entender mejor las diferentes dimensiones en la percepción del riesgo apuntadas más arriba, hemos realizado una primera aproximación a tres casos que consideramos relevantes para ilustrar la multidimensionalidad de la percepción social de la energía nuclear. El primer caso es el de la central nuclear de Vandellós I, una central de primera generación que se empezó a construir en plena dictadura franquista y que en 1989 sufrió un grave incidente que llevó a su desmantelamiento. El segundo caso es el de la central nuclear de Valdecaballeros, de segunda generación, que en una fase avanzada de su construcción, ya en pleno periodo democrático, fue afectada por la moratoria nuclear y nunca llegó a ponerse en marcha. El tercer caso consiste en el proceso de búsqueda de un emplazamiento para almacenar residuos radioactivos de todas las centrales españolas (ATC o Almacén Temporal Centralizado). Son tres casos ejemplares que han generado intensos debates sociales pero respondiendo a lógicas muy diferentes, y que consideramos que pueden ayudar a ilustrar nuestros argumentos respecto a la multidimensionalidad de la percepción del riesgo.

Para cada caso hemos identificado los principales actores, clasificados en cuatro grupos de acuerdo con las posiciones estructurales típicas de los conflictos socioambientales:

- "Promotores": Aquellos actores con intereses en la promoción de la energía nuclear. 
- "Afectados" (o "receptores"): Aquellas personas $o$ entidades que se perciben expuestas a las infraestructuras nucleares (de manera positiva o negativa). Pueden tener un mayor o menor grado de formalización (en forma de asociaciones, etc.). También se les puede denominar "receptores", en el sentido de que reciben el impacto (positivo o negativo) de la instalación nuclear.

- Autoridades públicas y "Reguladores": Son los actores a quienes corresponde regular las relaciones entre los anteriores, normalmente organismos públicos de diferentes niveles jerárquicos y/o territoriales. Aquí lo consideramos en un sentido amplio, más allá del regulador estricto (que sería el Consejo de Seguridad Nuclear).

- Además de estos tres actores principales, hemos considerado la opción "Otros" para incluir a instituciones científicas, expertos, instancias judiciales o medios de comunicación que pueden posicionarse dando apoyo a cualquiera de los anteriores.

A diferencia de otros tipos de conflictos ambientales, en los que instituciones públicas como ayuntamientos, gobiernos autónomos, etc., suelen formar parte de los "reguladores" en virtud de su capacidad de regular aspectos relativos al funcionamiento o instalación de las infraestructuras (pues tienen competencias legales para dar licencias, exigir condiciones, etc.), en el caso del riesgo nuclear estas entidades suelen tener una posición diferente pues no disponen de demasiada capacidad de decisión sobre el proyecto. Por ello, aquí los hemos clasificado como parte de los grupos "receptores" de las consecuencias, positivas o negativas, de los proyectos nucleares.

La metodología utilizada para el análisis de los tres casos de estudio ha consistido en:

1. Identificar los principales actores de cada caso (los protagonistas del conflicto).

2. Identificar qué argumentos usan para justificar su posición en el conflicto.
3. Interpretar sobre qué dimensiones del riesgo, de las expuestas en nuestro marco teórico, se encuadran dichos argumentos.

Se trata de un ejercicio exploratorio, basado en el análisis documental de fuentes escritas (declaraciones a periódicos, páginas web, informes, libros, etc.), cuya única finalidad es clarificar e ilustrar la propuesta teórica de este artículo. En un anexo se citan las fuentes documentales correspondientes a cada caso.

\section{Caso 1: Vandellós I}

Vandellós I se construyó durante los años 60 y entró en funcionamiento en 1972, durante los llamados "años dorados" de la energía nuclear en España. Es la única central nuclear española fabricada con tecnología francesa, con un diseño muy diferente a las restantes. En 1989 sufrió un grave accidente que llevó a su cierre anticipado.

\section{Fase 1: Construcción y Operación (1972-1988)}

Durante la fase de construcción y operación tanto los promotores como los reguladores y otras instituciones públicas (municipios principalmente) se mostraban plenamente tecno-optimistas. Las autoridades locales consideraban que la central nuclear comportaría unos salarios altos y un crecimiento económico para el territorio similar al que podrían dar la industria o el turismo (Costa Morata 1976). El director de la central de Vandellós I en una entrevista a la prensa declaraba que las personas que mueren en accidentes de tráfico causados por el turismo deberían suscitar más preocupación que los accidentes nucleares (El Correo Español 21-09-1974, citado en Costa Morata 1976). Antes de que el municipio de Vandellós fuera seleccionado para albergar la central nuclear, otras localidades cercanas fueron también candidatas. Una de ellas era l'Atmella de Mar, que fue desestimada a causa de la fuerte oposición social de la comunidad local y del ayuntamiento. Los principales opositores eran los pescadores locales, preocupados por la potencial contaminación de los

Tabla 2

Principales actores del caso Vandellós I

\begin{tabular}{|l|l|}
\hline Promotores & $\begin{array}{l}\text { Hifrensa (Hispano-Francesa de energía nuclear S.A) } \\
\text { ENRESA (Empresa Nacional de Residuos Radioactivos) (en la fase de desmantelamiento) }\end{array}$ \\
\hline $\begin{array}{l}\text { Autoridades públicas \& } \\
\text { Reguladores }\end{array}$ & $\begin{array}{l}\text { CSN: Consejo de Seguridad Nuclear } \\
\text { Ministerio de Industria }\end{array}$ \\
\hline $\begin{array}{l}\text { Afectados o } \\
\text { Receptores }\end{array}$ & $\begin{array}{l}\text { Administraciones públicas de diferentes niveles, nacional, regional y local (Vandellós) } \\
\text { Otros municipios preocupados: L'Ametlla de Mar, Pratdip, Montroig del Camp y Tivissa } \\
\text { Movimientos ambientalistas: Ecologistas en acción } \\
\text { Comisiones Obreras (trabajadores de la central) }\end{array}$ \\
\hline Otros & $\begin{array}{l}\text { El juzgado de Tarragona (el accidente fue llevado a juicio en el Juzgado de tercera instancia de Tarragona) } \\
\text { Científicos: Instituto de Investigaciones Pesqueras }\end{array}$ \\
\hline
\end{tabular}


recursos marinos (Martínez López 2004), y las potenciales consecuencias de la central sobre sus actividades económicas, su trabajo y sus formas de vida. Dado que no conseguían información fiable por parte de los promotores de la central ni de los reguladores, encargaron un estudio al Instituto de Estudios Pesqueros (CSIC).

\section{Fase 2: El accidente y el juicio (1989-1998)}

Esta segunda fase empezó con un incendio en Vandellós I (en 1989). Las fuentes indican que el fuego tuvo lugar el 19 de octubre cuando el aceite lubricante de una turbina atascada se empezó a quemar (Foro Nuclear 2016). La Agencia Internacional de la Energía Atómica (IAEA) declaró el incidente de Vandellós I como el peor en una instalación nuclear después de Chernóbil (El País 2510-1989), aunque posteriormente la IAEA se desdijo de esta afirmación (WISE 1989). El incidente fue clasificado como de nivel 3 (major incident) en la escala INES. El año 1986 el Consejo de Seguridad Nuclear (CSN) ya había advertido deficiencias y había reclamado mejoras de seguridad que en el momento del accidente todavía no se habían aplicado. Se iniciaron acciones judiciales contra los responsables de la central (promotores) y contra un responsable del CSN (regulador), aunque finalmente la sentencia fue absolutoria. Esta fase 2 finalizó con el desmantelamiento de la central nuclear, por la presión popular y, principalmente, por las duras condiciones impuestas por el regulador para poder retomar la actividad. Al principio, el CSN (regulador) y el gobierno aseguraron que no se vertió radiación al exterior, pero más tarde las autoridades anunciaron que la cantidad de radiación emitida no era significativa y que por tanto no había peligro para la población residente en los alrededores (WISE 1989), lo cual suponía una contradicción que inducía a desconfiar de la información proporcionada.

El sindicato Comisiones Obreras (CCOO) que representaba a los bomberos (afectados) se quejó por los riesgos personales de estos, ya que el plan de emergencia (PENTA) no estaba plenamente desplegado y aquellos trabajadores no disponían del equipamiento adecuado ni de la formación necesaria para actuar en instalaciones nucleares, ni habían sido advertidos sobre el riesgo de radioactividad. Otros actores (afectados) del territorio reconocieron también la gravedad del incidente, como los alcaldes de cuatro municipios vecinos (L'Atmella de Mar, Pratdip, Montroig, Tivisa) y otras organizaciones de la sociedad civil, que organizaron manifestaciones para exigir el cierre de la planta.

\section{Fase 3: Cierre y desmantelamiento (1991 a 2027)}

El tercer periodo, todavía en marcha, es el del proceso de cierre y desmantelamiento, durante el cual los promotores mantienen una retórica principalmente basada en el control técnico. Así, en una entrevista concedida a un periódico (El País 2005), el director de la central (promotor) subraya el conocimiento técnico y la experiencia que supone el pilotar el proceso de desmantelamiento y los elevados niveles de fiabilidad que pueden garantizar, lo cual se reivindica como un ejemplo a nivel internacional en este ámbito. Los ayuntamientos de la zona relatan también el hecho de que la población ya está muy "familiarizada" con los riesgos a los que están expuestos, en especial en el caso de Vandellós (municipio en el que en 1980 se empezó a construir una nueva central nuclear, Vandellós II, que entró en funcionamiento en 1988 y todavía está operativa). Además de la familiaridad, los ayuntamientos vecinos valoran positivamente el acceso a información sobre la gestión del riesgo (Costa Morata 2011). En 2014, dejando claro que la seguridad debería primar sobre todo lo demás, el alcalde de Vandellós valoraba el impacto de la central nuclear en el territorio como muy positivo por los empleos generados y la generación de riqueza en el municipio (El Diario.es 20-10-2014).

Los movimientos sociales relacionados con la defensa ambiental alertaron de que las condiciones técnicas de la central nuclear no eran las adecuadas y sostuvieron que el incidente se debería haber comunicado antes, puesto que el propio regulador (CNS) ya había exigido reformas en 1986, lo que indicaba que ya se habían detectado deficiencias con anterioridad (Terra-Ecología Práctica 2014). La organización Ecologistas en Acción realizó un informe sobre la situación de Vandellós I denunciando que los riesgos ambientales y sociales siempre suelen dejarse en segundo plano cuando se toman decisiones sobre instalaciones energéticas (Ecologistas en Acción 2014).

\section{Caso 2: Valdecaballeros}

La de Valdecaballeros forma parte de la segunda generación de centrales nucleares en España. Autorizada en 1979, su origen parte de una propuesta de 1972 para dotar a la región de Extremadura de desarrollo económico y energético. El emplazamiento de la central ilustra los requerimientos que se buscaban a principios de los 70 , básicamente áreas rurales despobladas técnicamente apropiadas. El municipio de Valdecaballeros tenía cuatrocientos habitantes y asumió favorablemente la llegada de cinco mil trabajadores, la gran mayoría ajenos al territorio. La documentación disponible muestra que la llegada de la central nuclear contó con el apoyo de buena parte de la población local y de las autoridades locales (Costa Morata 2011; Gaviria et al. 1978). En 1984 el Gobierno español (de la mano del recién llegado partido socialista) decretó una moratoria nuclear que paralizó la construcción cuando los trabajos estaban realizados al $70-80 \%$. 
Tabla 3

Principales actores del caso Valdecaballeros

\begin{tabular}{|l|l|}
\hline Promotores & Unión Eléctrica, Hidroeléctrica Española y Sevillana de Electricidad \\
\hline $\begin{array}{l}\text { Autoridades públicas \& } \\
\text { Reguladores }\end{array}$ & $\begin{array}{l}\text { CSN } \\
\text { Gobierno nacional }\end{array}$ \\
\hline Receptores / Afectados & $\begin{array}{l}\text { Gobierno autonómico } \\
\text { Gobiernos locales }\end{array}$ \\
\cline { 2 - 2 } & $\begin{array}{l}\text { Agricultores (comunidades de regantes) } \\
\text { Otros municipios vecinos } \\
\text { Movimientos sociales ambientales: Comisión de defensa del Guadiana; Ecologistas de Extremadura } \\
\text { Habitantes de Valdecaballeros }\end{array}$ \\
\hline Otros & Expertos científicos \\
\hline
\end{tabular}

\section{Fase 1: 1975-1983}

Durante esta primera fase, el promotor de Valdecaballeros expresa una retórica tecno-optimista en la que el desarrollo nuclear se presenta vinculado al progreso económico y tecnológico. Así, el posible impacto ambiental de la central se plantea como una ventaja porque "el calor emitido por la planta nuclear, sobre 30 grados centígrados en invierno, dará lugar a un clima tropical a las reservas turísticas naturales del Guadiana. Un cambio en el clima que será una ventaja también para la agricultura de la zona" (Diario Ya 25-10-1974, citado en Costa Morata 1976). El argumento económico es el que se usa para justificar su emplazamiento en Valdecaballeros. De hecho, la propia construcción de la central fue enmarcada dentro del concepto de una especie de Plan Marshall energético para Extremadura, "la Siberia de España", aludiendo así a una región desfavorecida que se desarrollaría gracias a la energía nuclear (Baigorri 1999). En este sentido, durante la fase de construcción, la central se percibía como una fuente de riqueza. En palabras de Marino Sierra (posterior alcalde), "todos los pisos se alquilaron, multitud de trabajadores llegaron [...] y se esperaban más beneficios, no solo durante la fase de construcción sino también debido a los beneficios de la operación de la central. Los municipios nucleares reciben cantidades sustanciales de dinero del gobierno, para la creación de empleos y otras actividades" (Canal Extremadura 2015).

Sin embargo, los alcaldes de aquel momento de Valdecaballeros y del municipio vecino de Castiblanco introducen argumentos políticos en el debate, cuestionando el proceso de decisión sobre el emplazamiento de la central nuclear porque lo percibían como eminentemente político (y no técnico) y "desde arriba" (Costa Morata 2011: 115). No obstante, todo parece indicar que, durante la fase de construcción (1975), el desacuerdo entre los sectores pro $y$ anti nucleares fue evidente. Mientras unos remarcaban los argumentos económicos y de generación de riqueza para el municipio, otros argumentaban temas de seguridad y de potenciales efectos en la salud: "el pueblo no quería la central, diga lo que diga ahora la gente. Eran cuatro los que la querían. Los de las tierras y los obreros. Y con las cosas de la salud, con los asuntos de la seguridad de los hijos, no se juega ni por todo el dinero y menos si el dinero es solo prometido" (palabras de un vecino al diario Público 29-12-2008). La división existente entre los habitantes del lugar se hizo patente incluso en la coexistencia diaria. Como uno de los vecinos afirma: "Dio mucho trabajo mientras se construía, sí. Pero por primera vez en este pueblo en el que nací vi que se rompía la solidaridad, que empezaban las envidias" (Público 29-12-2008).

En agosto de 1977 hubo una multitudinaria manifestación contra la central nuclear y reclamando la autonomía política regional que fue duramente reprimida, dando paso a una etapa en la que ambas reivindicaciones se presentaron unidas, de tal modo que en septiembre de 1979 más de un centenar de alcaldes de la región extremeña en huelga de hambre se encerraron en el ayuntamiento de Villanueva de La Serena (Badajoz) protestando contra la central y por la reivindicación territorial autonómica (Baigorri 1999). Además, los movimientos sociales ambientalistas denunciaron la desigual distribución del riesgo entre territorios, y el hecho de que se hubiera escogido Valdecaballeros porque era un pueblo suficientemente apartado como para albergar una industria peligrosa (Costa Morata 2011).

\section{Fase 2: 1983 (la moratoria)}

Durante este periodo las políticas reguladoras de la energía nuclear experimentaron un cambio drástico. En 1982 el partido socialista (PSOE) ganó las elecciones y en pocos meses, ante la crítica situación financiera de los promotores (Martínez López 2004), proclamó una moratoria nuclear. Además, la reestructuración institucional del estado español en Comunidades Autónomas facilitó que los nuevos gobiernos autonómicos tuvieran que demostrar su sensibilidad a las demandas de su región. En este 
contexto, varios proyectos nucleares fueron paralizados por los nuevos gobiernos autónomos, como fue el caso de Valdecaballeros. "Decir no a la central nuclear, además de por motivos ambientales, era una forma de mostrar a la gente de Extremadura que el poder político regional podía enfrentarse tanto al poder económico como al Gobierno central" (Público 29-12-2008). Así, ante la dura oposición del gobierno de Extremadura, el gobierno español (PSOE) incluyó a Valdecaballeros entre las centrales afectadas por la moratoria nuclear.

Durante este periodo (años 80 y 90 ) las preocupaciones de riesgo expresadas eran fundamentalmente las de aquellos actores que vivían en las áreas territoriales cercanas, pero no tanto en el mismo municipio, donde las actitudes solían ser mucho más favorables a la central (Costa Morata 2011). Un policía local, por ejemplo, recordaba que "la gente pasó de ganar cuatro duros a tener un sueldo fijo, y gracias a eso el pueblo se reconstruyó entero" (EI Mundo 15-11-2015). El gobierno municipal intentó continuar con la construcción de la planta nuclear después de la moratoria. De acuerdo con el alcalde de entonces "los trabajadores se movilizaron con huelgas, la gente estaba muy preocupada, algunas asambleas en el ayuntamiento, reuniones con el gobierno de Extremadura, ocupamos la iglesia... hicimos muchas cosas pero no sirvieron de nada" (Marino Sierra, exalcalde de Valdecaballeros en declaraciones a Canal Extremadura, 2015).

Por otro lado, los movimientos ambientales locales tuvieron una percepción negativa del crecimiento económico que supuestamente la central nuclear proveería, ya que argumentaban que la mayoría serían de muy corta duración y la presencia de la central sería un obstáculo para el desarrollo de otras actividades económicas como la agricultura, el turismo, etc. Como apuntaba uno de los responsables de Ecologistas de Extremadura "por supuesto, hubo sacrificios [...] pero se equivocaron respecto al empleo. Al principio había mucho pero luego se acabó el trabajo. Como en Almaraz. Ese es el riesgo. Ellos te dan cosas, pero también te las quitan [...] La central nuclear quitó mucha agua al regadío, a los agricultores y ganaderos, al turismo..." (Público 29-12-2008). De hecho, las comunidades de regantes de la región fueron uno de los principales actores contrarios a la central nuclear, puesto que percibieron posibles problemas de coexistencia con los requerimientos de agua de la misma (Martínez-Alier 2016).

\section{Fase 3: Desde la moratoria en adelante}

Cuando el desmantelamiento de la central nuclear se hizo realidad el gobierno local no compartió la decisión. Así, a lo largo de los años, varios alcaldes del municipio han demandado compensaciones por los daños económicos que han tenido a causa de que la central nuclear no se pusiera en marcha; así como por la falta de proyectos alternativos. Uno de los alcaldes, el socialista Miguel Ángel García, envió un acuerdo del pleno al gobierno autonómico (también en manos socialistas) argumentando que "Valdecaballeros se sacrificó por el bien común", y detallando una serie de proyectos para los terrenos de la central que nunca se desarrollaron (Público 29-12-2008). Las propuestas fueron, por ejemplo, la construcción de una central térmica de ciclo combinado, o una planta hidroeléctrica aprovechando la infraestructura del embalse construido. La última propuesta consistía en la instalación de dos plantas termo-solares y dos plantas fotovoltaicas en los terrenos que ocupa la central. En opinión de David Baños, otro de los alcaldes que ha tenido Valdecaballeros, la instalación de las plantas de energías renovables supondría una notable inversión económica y una fuente de recursos impositivos para el ayuntamiento, pero el Gobierno español ha rechazado la propuesta, presumiblemente por si acaso España apostara de nuevo por la energía nuclear en el futuro (El Periódico de Extremadura, 30-01-2011).

\section{Caso 3: El almacén de residuos nucleares (ATC)}

EI VI Plan General de gestión de residuos radiactivos, impulsado por la Empresa Nacional de Residuos (ENRESA) y aprobado por el Consejo de Ministros el 23 de junio de 2006, dio prioridad a la construcción de un lugar para almacenar los residuos nucleares generados por las centrales nucleares españolas (Almacén Temporal Centralizado - ATC). Esto dio lugar a un proceso inédito, que introducía transparencia y participación, para elegir el emplazamiento. Los municipios que solicitaron la candidatura fueron 14, de los que 8 fueron admitidos como candidatos firmes. Aquí analizaremos solo las controversias que se dieron alrededor de la candidatura de Ascó (Tarragona), sobre la que se desarrolló una intensa campaña para lograr emplazarlo en un municipio que ya contaba con una larga historia de conflictos nucleares, así como sobre la localidad finalmente escogida, Villar de Cañas (Cuenca). Otros autores han analizado el conflicto generado en otros de los municipios candidatos, como el de Zarra (Valencia) por Ernest García (2011), o el análisis del proceso en general por Costa Morata y Baños (2010). El proceso encalló en septiembre de 2015 tras un cambio político en el gobierno autónomo de Castilla-La Mancha, pero la propuesta sigue en marcha.

\section{Fase 1: El proceso de candidaturas (2009) (con particular atención al caso de Ascó)}

Los organismos públicos han justificado el emplazamiento del ATC en términos de "diversificación económica”, ya que está prevista la construcción de un centro tecnológico junto al almacén nuclear que contribuiría a diversificar los medios de vida en el territorio en cuestión. El responsable del Ministerio de Indus- 
Tabla 4

Principales actores del caso ATC

\begin{tabular}{|c|c|}
\hline Promotores & - ENRESA \\
\hline $\begin{array}{l}\text { Autoridades públicas } \\
\text { \& Reguladores }\end{array}$ & $\begin{array}{l}\text { - Consejo de Seguridad Nuclear } \\
\text { - Comisión Interministerial para el ATC }\end{array}$ \\
\hline \multirow[b]{2}{*}{$\begin{array}{l}\text { Afectados / } \\
\text { Receptores }\end{array}$} & $\begin{array}{l}\text { - Gobiernos autonómicos: Parlamento de Cataluña, Gobierno de Castilla-La Mancha } \\
\text { - Gobiernos municipales: ayuntamiento de Ascó, ayuntamiento de Villar de Cañas }\end{array}$ \\
\hline & $\begin{array}{l}\text { Organizaciones sociales y movimientos ambientales: } \\
\text { - Anti: CANC (Coordinadora anti-cementiri nuclear de Catalunya), Plataforma contra el Cementerio Nuclear } \\
\text { en Cuenca, Greenpeace, Ecologistas en Acción } \\
\text { - Pro: Grup Veïnal Ribera d’Ebre, Volem viure a Flix, Plataforma A.S.C.O. y Volem viure a Riba-roja, } \\
\text { Agrupación de Empresas de Villar de Cañas, Plataforma Sí queremos el ATC en Villar de Cañas }\end{array}$ \\
\hline Otros (expertos) & $\begin{array}{l}\text { - Instituto de Salud Carlos III } \\
\text { - CADS (Consell Assessor per al Desenvolupament Sostenible) } \\
\text { - Instituto de Geología } \\
\text { - Tribunal Superior de Justicia de Castilla y La Mancha. Y Consejo de Transparencia Pública }\end{array}$ \\
\hline
\end{tabular}

tria de la época (Miguel Sebastián) afirmó que otras opciones como los ATI (Almacenes Temporales Individualizados) son más caras y menos seguras (Prades 2015). El alcalde de Ascó usó argumentos muy similares para apoyar la candidatura del municipio: intereses económicos y desarrollo local (íbid. 181). En cambio, el Parlamento catalán adoptó una posición diferente y rechazó la propuesta del almacén de residuos nucleares en Cataluña hasta en tres ocasiones. Teniendo en cuenta las complejas interacciones entre el Gobierno español y el catalán, este rechazo se puede interpretar como parte de la estrategia de desafío al gobierno central (similar a lo que sucedió en el caso de Valdecaballeros en Extremadura).

En cuanto a la población afectada (o receptora), se encuentran tanto argumentos a favor como en contra. Por ejemplo, varias plataformas ciudadanas y movimientos sociales, algunas ya existentes y otras creadas para la ocasión (como la CANC - Coordinadora Anti-Cementiri Nuclear de Catalunya) argumentaron su oposición al proyecto en los siguientes términos (Prades 2015):

- Amenaza a la salud pública, una mala herencia para las generaciones futuras (altos niveles de radioactividad por cientos de años).

- Elevados costes de la gestión de los residuos radioactivos que deberán ser pagados con recursos públicos.

- Carga territorial: Cataluña tiene ya tres centrales nucleares en funcionamiento y una en proceso de desmantelamiento. Una nueva instalación nuclear sería ya excesiva.

- Limitaciones de un proceso de implicación real con los actores relevantes, incluyendo las organizaciones ambientalistas y otros movimientos ciudadanos.
- El ayuntamiento de Ascó tomó la decisión de presentar la candidatura sin proceso informativo ni participativo previo.

- Se podrían probar otras opciones tecnológicas con menos riesgos, evitando el transporte a larga distancia y mantenimiento de los residuos radioactivos.

Por otro lado, varias asociaciones locales y entidades comunitarias se posicionaron en favor del almacén de residuos radioactivos, como el Grup Veïnal Ribera d'Ebre, Volem viure a Flix, la plataforma A.S.C.O. o Volem viure a Riba-roja (Prades 2015), justificando su posicionamiento en los siguientes argumentos:

- EI ATC es una infraestructura pasiva, que comportaría unos riesgos similares a los de una instalación industrial convencional.

- El ATC generaría nuevas oportunidades económicas para el territorio.

- La industria nuclear puede convivir con otros relevantes motores económicos, como la producción de alimentos con denominación de origen y el turismo.

\section{Fase 2: La designación de Villar de Cañas (2011)}

En 2011 el gobierno español decidió que el ATC se emplazaría en Villar de Cañas (Cuenca). ENRESA (promotor) argumentó que sería beneficioso para la región porque se crearían centenares de empleos durante el proceso de construcción, así como que se trata de una tecnología efectiva y segura, ya probada en otros países europeos (en Holanda, Suecia, Francia, etc.), y permitiría a España alcanzar la excelencia científica generando empleos de alto nivel científico en el territorio (Enresa 2011). 
Una vez más, entre la población afectada (receptores) se dieron diferentes posiciones ante el ATC, acompañadas de los respectivos argumentos. Organizaciones ecologistas, como Greenpeace o Ecologistas en Acción, han sido protagonistas activos del proceso (Prades 2015):

- Argumentando que el emplazamiento fue escogido por razones políticas más que técnicas, pues no es adecuado ni la calidad del terreno ni está próximo a instalaciones nucleares.

- Criticando la actuación del CSN porque, desde su punto de vista, el regulador tramitó la autorización preliminar del emplazamiento sin suficiente información y a pesar de existir serias dudas entre expertos de la propia institución.

- Argumentando que el transporte de residuos nucleares puede comportar riesgos graves porque el trayecto pasaría por 216 municipios, que tendrían también derecho a información y participación pública sobre el proyecto, cosa que no se ha dado.

La Plataforma contra el Cementerio Nuclear en Cuenca, formada por 49 organizaciones sociales, ambientales y ciudadanas, declaró su rechazo al emplazamiento por los siguientes motivos (PCNC 2016):

- Va en contra de su propuesta de un desarrollo local basado en energías renovables, turismo sostenible e industria alimentaria de calidad.

- Consideran que el transporte de residuos puede ser un problema porque la seguridad no está probada.

- Consideran que no hay un consenso social real.

- Sostienen que experiencias similares en otras áreas han mostrado que no se genera riqueza con este tipo de instalaciones.

- Y además, temen que los valores naturales y culturales de las áreas circundantes puedan ser dañados (pérdida de turismo y del valor de su herencia cultural histórica).

Simultáneamente, varias asociaciones y movimientos locales aparecieron dando apoyo a la elección de Villar de Cañas, implicando a ciudadanos y trabajadores en el desarrollo de los trabajos. Por ejemplo, la Asociación de Empresas de Villar de Cañas o la Plataforma Sí queremos el ATC en Villar de Cañas. Sus argumentos eran principalmente de tipo económico (creación de empleo, desarrollo comarcal, progreso industrial, etc.).

\section{Fase 3: Interrupción (2015)}

ENRESA (el promotor) insiste en los argumentos de la creación de empleo, de inversión económica y de una infraestructura tecnológica pionera. El Gobierno español, a su vez, argumenta que detener los trabajos causaría pérdidas económicas, 51 millones por año (y un incremento en la factura eléctrica del $25 \%$ o $30 \%$ ), e insiste en que la decisión se tomó con un importante consenso social, territorial e institucional. Pero el gobierno autónomo (de Castilla-La Mancha) argumenta irregularidades en el planeamiento, y advierte de que no se dan las garantías de seguridad necesarias porque existen informes externos contradictorios, y porque está previsto aumentar la zona ZEPA. De hecho, el Colegio Oficial de Geólogos y los expertos del CSN (Área de Ciencias de la Tierra) expresan también sus dudas sobre la viabilidad del emplazamiento, advirtiendo de posibles costes económicos adicionales. Los ayuntamientos de la zona expresan su preocupación por la ampliación de la zona ZEPA, que podría ocasionar pérdidas a agricultores y al desarrollo del ATC. El alcalde de Alconchel de la Estrella (municipio vecino) afirma que ENRESA (promotor) ofreció 12.000 euros anuales hasta que el ATC empezara a funcionar, lo que se interpreta como una estrategia para convencer a la oposición.

Los principales movimientos sociales ambientales (Greenpeace y Ecologistas en Acción) siguen argumentando su posición contraria al ATC por los motivos anteriormente citados.

\section{Comparación de los tres casos}

Mediante el análisis realizado hemos podido registrar un amplio abanico de argumentos utilizados por los diversos actores protagonistas de las controversias nucleares en España. Se ha podido observar en la opinión pública española una evolución de actitudes de relativo desinterés en los años 70 hacia posiciones mayoritariamente contrarias a la energía nuclear a partir de finales de aquella década y sobre todo de los años 80 , manteniéndose desde entonces en un $60-70 \%$ de actitudes antinucleares según las encuestas disponibles, con pocas fluctuaciones hasta hoy día. Unas encuestas que no consiguen capturar la multidimensionalidad de las percepciones de riesgo en este tipo de conflictos socioambientales.

Por otro lado, al analizar los casos concretos y los argumentos de los diferentes actores implicados en las controversias, se observa que los diferentes actores coinciden en pocas de las dimensiones de percepción del riesgo.

La percepción de los "promotores" de la energía nuclear se caracterizó principalmente por:

[A] Una retórica tecnooptimista que, en los orígenes, tiende a subestimar los problemas ambientales y a enfatizar la fiabilidad, seguridad y eficiencia de la tecnología nuclear y de su gestión. Incluso los potenciales impactos ambientales se tienden a reinterpretar de manera positiva (por ejemplo, se afirma que la agricultura se beneficiará del posible cambio del clima a nivel local). 
[B] Un enfoque riesgo-beneficio, desde el que, aún reconociendo que existen ciertos riesgos, se asume que siempre serán compensados por los beneficios.

En cuanto a las autoridades públicas con competencias sobre el tema, coinciden en gran medida con los argumentos de los "promotores", y tienden a poner el énfasis en:

[C] Los empleos que puede llegar a crear en áreas rurales o en crisis

[D] Los aspectos de seguridad y fiabilidad de la tecnología (valorados positivamente).

Entre la población afectada o "receptores", encontramos diferentes tipos de respuestas. Por un lado, entre la población afectada y los movimientos sociales ambientales se observan los siguientes argumentos:

[E] Preocupación por la disrupción de las formas de vida de la población local (cambios en actividades productivas, en valores naturales y culturales, etc.).

[F] Las instalaciones potencialmente peligrosas no se perciben distribuidas con suficiente equidad en el territorio (déficits en términos de justicia ambiental).

[G] Existe desconfianza respecto a la gestión que las empresas del sector y los reguladores hacen del riesgo nuclear.

[H] Se echa en falta un mayor grado de participación pública, una extensión de la democracia participativa en la toma de decisiones sobre los desarrollos nucleares.

[l] Hay preocupación también por la contaminación del territorio y los posibles daños a la salud por radiaciones o accidentes.

También existen grupos sociales a nivel local que se posicionan en favor de la energía nuclear, principalmente algunos sectores de los municipios concretos donde se emplazan las infraestructuras nucleares. Sus principales argumentos parecen ser:

[J] La familiaridad con la energía nuclear (principalmente en casos de territorios que cuentan con estas instalaciones desde hace décadas).
[K] Valoración positiva de los beneficios económicos originados por su instalación en el territorio.

[L] No perciben que los riesgos nucleares sean superiores a los de otras actividades industriales.

Los ayuntamientos y gobiernos locales han solido ser más receptivos a aquella retórica economicista, de tal manera que en aquellas localidades donde se emplazaban infraestructuras nucleares se argumentaba en términos de:

[M] La creación de puestos de trabajo, de indemnizaciones o compensaciones para el municipio, etc.

[N] Sin embargo, se observa también que incluso estos gobiernos locales, en ocasiones, tienden a argumentar una cierta desconfianza por las promesas incumplidas de los gobiernos regionales o central en el pasado.

[O] Finalmente, se observa que las instituciones públicas de ámbito regional (autonómico) e incluso nacional han ido cambiando de posiciones a lo largo del tiempo, en ocasiones jugando la carta antinuclear como un modo de legitimarse ante un electorado escéptico con las nuevas instituciones regionales, generando cohesión entre sus afines (caso de Extremadura en los años 80, con Valdecaballeros), o bien como expresión de poder ante otras autoridades políticas o institucionales (caso de Cataluña en los últimos años, con el ATC).

Situando todos estos argumentos en una tabla podemos observar su distribución entre las dimensiones de percepción del riesgo propuestas en nuestro marco teórico (Tabla 5), evidenciando dónde pone el acento cada actor a la hora de justificar su posición.

\section{Conclusiones}

En el presente texto hemos presentado un marco teórico que integra aportaciones de varias tradiciones sobre percepción de riesgos. A partir de series históricas de encuestas y de la descripción (exploratoria) de tres casos, hemos intentado dar cuenta de las dimensiones que conforman la percepción del riesgo nuclear. El análisis muestra cómo los actores protagonistas de los conflictos nucleares utilizan argumentos relativamente dis-

Tabla 5

Distribución de los principales argumentos de los actores por dimensiones de percepción del riesgo

\begin{tabular}{|l|l|l|l|}
\hline Dimensiones & Promotores & Autoridades públicas & Receptores \\
\hline Salud y medio ambiente & A & D & I, L \\
\hline Económicas & B & C & K, M \\
\hline Socioculturales & & & E, J, O \\
\hline Político-institucionales & & & F, G, H, N \\
\hline
\end{tabular}

Nota: Las letras corresponden a los códigos asignados a cada argumento en los párrafos anteriores. 
pares, y permite entender cuál es la dimensión de percepción del riesgo que ponen de relieve en cada caso. En términos generales, mientras promotores y reguladores suelen poner el acento en las dimensiones de "salud/medioambiente" (garantizando seguridad y minimizando posibles daños en estos ámbitos), y en dimensiones "económicas" (valorando la riqueza que puede aportar al territorio), los grupos opositores incluyen además dimensiones "socioculturales" (pues perciben las infraestructuras nucleares como una amenaza a sus formas de vida y actividades cotidianas) y dimensiones "politicoinstitucionales" (principalmente por la desconfianza percibida hacia las instituciones encargadas de gestionarlas). Significativamente, promotores y reguladores tienden a desestimar este tipo de argumentos, prefiriendo centrar la discusión en aspectos técnicos de seguridad, ambientales y económicos, sin tener en cuenta que dichas dimensiones sí son relevantes para una parte de la población, especialmente para la que se suele posicionar más contraria a los proyectos nucleares. Desde nuestra perspectiva no es posible entender las respuestas sociales a la energía nuclear, y por tanto gestionar adecuadamente los conflictos que se puedan derivar, sin tener en cuenta el conjunto de las cuatro dimensiones propuestas.

Se observa también que las encuestas de opinión pública sobre energía nuclear no prestan adecuada atención a indicadores que vayan más allá de la percepción de potenciales impactos (positivos o negativos) a la salud, al medio ambiente o al desarrollo económico, dejando fuera la mayor parte de indicadores socioculturales (como atributos subjetivos del riesgo, impactos sobre identidades sociales, territoriales o políticas, o sobre tradiciones y valores, incluyendo imaginarios militares), e indicadores politicoinstitucionales (como todo lo relacionado con la confianza en las instituciones -promotoras y reguladoras-, en el sistema político o las percepciones de (in)justicias o agravios comparativos). Se trata de un déficit que habría que subsanar para poder captar toda la complejidad de las percepciones de riesgo.
Por otro lado, la cercanía entre los argumentos de promotores y de reguladores es algo esperable en una tecnología como la nuclear, que requiere de un entorno económico e institucional favorable a grandes inversiones, solo alcanzable con un fuerte compromiso del sector público (tal como advertían Rubio-Varas et al. 2017). El hecho de que su desarrollo solo pueda hacerse mediante megaproyectos muy intensivos en uso de recursos públicos y privados, que una vez en marcha son difícilmente reversibles (creando path-dependency), probablemente sea una de las principales características de la energía nuclear (Flyvbjerg et al. 2003), lo cual inevitablemente genera desajustes en su gestión en un contexto de apertura democrática de las instituciones, cada vez más interpeladas para introducir más voces en la toma de decisiones. Las demandas sociales en las democracias contemporáneas exigen una apertura de la toma de decisiones, de tal modo que las personas o colectivos afectados por el desarrollo de una tecnología potencialmente peligrosa dispongan de mecanismos para incluir sus puntos de vista en la toma de decisiones (European Commission 2002). No obstante, a pesar de los avances en esta dirección, hay dudas de que las características constitutivas de la energía nuclear (o su signature, en términos de Horlick-Jones et al. 2010) permitan dar una fácil respuesta a las inquietudes que los grupos opositores plantean en términos de dimensiones socioculturales y politicoinstitucionales.

\section{Agradecimientos}

Este artículo se ha elaborado parcialmente con datos provenientes del proyecto HONEST (History of Nuclear Energy and Society) (http://www.honest2020.eu), financiado por la Comisión Europea mediante la convocatoria Horizon 2020, programa formativo de Euroatom, Grant Agreement 662268. Queremos agradecer también los comentarios críticos de Ana Prades (CIEMAT-CISOT) a una primera versión de este texto.

\section{Referencias Bibliográficas}

Álvarez Miranda, A. 1990. "Necesidades energéticas de un mundo en progreso", Política Exterior 17 (4): 25-33.

Baigorri, A., M. Chaves y M. Caballero. 2015. "The nuclear debate in Spain: The persistence of rejection". Pp. 3453 en Energy and Society: Public Opinion, Policies and Sustainable Development, coordinado por A. Agustoni y M. Maretti. London: AuthorHouse.

Bárcena, I. 1995. "La evolución del movimiento ecologista vasco a través del espejo nacionalista". Pp. 13-66 en Nacionalismo y ecología. Conflicto e institucionalización del movimiento ecologista vasco, editado por I. Bárcena, P. Ibarra y M. Zubiaga. Madrid: La Catarata.
Besley, J. C. 2012. "Does fairness matter in the context of anger about nuclear energy decision making?". Risk Analysis 32: 25-38. https://doi.org/10.1111/j.15396924.2011.01664.x

Centro de Investigaciones Sociológicas (CIS). Encuestas sobre Energía (1978-2011). http://www.cis.es/cis/opencm/ES/1_ encuestas/estudios/listaTematico.jsp?tema=88\&todos=no [consultado el 19 de febrero de 2016].

Costa Morata, P. 1976. Nuclearizar España. Madrid: Troya.

Costa Morata, P. 2009. "La Transicion Ecológica En España, 1973-1983." Sociedad y Utopia. Revista de Ciencias Sociales 33: 265-285. 
Costa Morata, P. 2011. Ecologíada, 100 batallas: Medio ambiente y sociedad en la España reciente. Madrid: Biblioteca Nueva.

Costa Morata, P. y P. Baños Pérez. 2010. "Sociología e ideología de los residuos radiactivos: la sociedad contra la técnica". Argumentos de Razón Técnica 13: 137-158.

De la Torre, J. y M. Rubio-Varas. 2015. La financiación exterior del desarrollo industrial español a través del IEME (1950-1982). Madrid: Banco de España.

De la Torre, J. y M. Rubio-Varas. 2016. "Nuclear Power for a Dictatorship: State and Business Involvement in the Spanish Atomic Program, 1950-85." Journal of Contemporary History 51 (2): 385-411. https://doi. org/10.1177/0022009415599448

Dobson, A. 1997. Pensamiento político verde. Barcelona: Paidós.

Douglas, M. y A. Wildavsky. 1982. Risk and Culture. Berkeley: University of California Press.

Espluga, J., J. Farré, J. Gonzalo y A. Prades. 2014. "Factores que inhiben la movilización social: el caso del área petroquímica de Tarragona". Revista Española de Investigaciones Sociológicas 146: 191-216. http://dx.doi. org/10.5477/cis/reis.146.191

European Commission. 2002. Science and Society Action Plan. Luxembourg: Office for Official Publications of the European Communities.

Fernández, J. 1999. El ecologismo español. Madrid: Alianza.

Fischhoff, B., P. Slovic, S. Lichtenstein, S. Read y B. Coombs. 1978. "How Safe is Safe Enough: A Psychometric Study of Attitudes towards Technological Risk and Benefits". Policy Sciences 8: 127-152.

Flyvbjerg, B., N. Bruzelius y W. Rothengatter. 2003. Megaprojects and risk. Cambridge: Cambridge University Press.

Foro Nuclear Español (FNE). 2015. Encuesta de opinión pública sobre la energía nuclear. http://www.amac.es/wp-content/ uploads/2015/07/Resumen-encuesta-opni\%C3\%B3np\%C3\%BAblica-julio2015.pdf [consultado el 12/06/2017].

Fundación Encuentro. 2009. "Opinión pública y debate nuclear". Pp. 291-359 en Informe España 2009. Madrid: Fundación Encuentro.

García, E. 2011. "La problemática de la energía nuclear en el valle de Ayora". Arxius 25: 83-102.

Gaviria, M., J. M. Naredo y J. Serna (coords.). 1978. Extremadura saqueada. Recursos naturales y autonomía regional. Barcelona: Ruedo Ibérico.

Horlick-Jones, T., A. Prades y J. Espluga. 2010. "Investigating the degree of 'stigma' associated with nuclear energy technologies: a cross-cultural examination of the case of fusion power". Public Understanding of Science 21 (5): 514-533. https://doi.org/10.1177/0963662510371630

Irwin, A., P. Simmons y G. Walker. 1999. "Faulty environments and risk reasoning: the local understanding of industrial hazards". Environment and Planning A 31 (7): 1311-1326. https://doi.org/10.1068/a311311

Lemkow, L. 1984. La protesta antinuclear. Madrid: Mezquita.

Martínez Alier, J. 2016. "Valdecaballeros nuclear power station, Spain". EJATLAS: Mapping ecological conflicts and spaces of resistance. https://ejatlas.org/print/valdecaballeros-nuclear-power-station-spain [consultado el 12/06/2017]

Martínez López, L. 2004. "El movimiento ecologista. La lucha antinuclear y contra el modelo energético en España". Mientras Tanto 91-92: 83-106.

Otway, H. y J. J. Cohen. 1975. "Revealed Preferences: Comments on the Starr Benefit-Risk Relationships". Pp. 7580 en Research Memorandum. Laxenburg (Austria): International Institute for Applied Systems Analysis.
Otway, H. y M. Fischbein. 1976. "The Determinants of Attitude Formation: An Application to Nuclear Power". Pp. 76-80 en Research Memorandum. Laxenburg (Austria): International Institute for Applied Systems Analysis.

Otway, H. y D. von Winterfeldt. 1982. "Beyond Acceptable Risk: On the Social Acceptability of Technologies". Policy Sciences 14: 247-256.

Otway, H. y D. von Winterfeldt. 1992. "Expert Judgement in Risk Analysis and Management: Process, Context and Pitfalls". Risk Analysis 1, 12: 83-93.

Parkhill, K. A., N. F. Pidgeon, K. L. Henwood, P. Simmons y D. Venables. 2010. "From the familiar to the extraordinary: local residents' perceptions of risk when living with nuclear power in the UK". Transactions of the Institute of British Geographers 35: 39-58. https://doi. org/10.1111/j.1475-5661.2009.00364.x

Pidgeon, N. F., I. Lorenzoni y W. Poortinga. 2008. "Climate change or nuclear power-No thanks! A quantitative study of public perceptions and risk framing in Britain". Global Environmental Change 18: 69-85. https://doi. org/10.1016/j.gloenvcha.2007.09.005

Poortinga, W., N. Pidgeon e I. Lorenzoni. 2006. "Public perceptions of nuclear power, climate change and energy options in Britain: summary findings of a survey conducted during October and November 2005". Understanding Risk Working Paper 06-02. Norwich: Centre for Environmental Risk.

Prades, A. 1997. Energía, tecnología y Sociedad. Madrid: Ediciones de la Torre.

Prades, A., J. Espluga y T. Horlick-Jones. 2015. "Riesgos tecnológicos, conflictos sociales y políticas ambientales. Del estudio de las percepciones a la implicación pública". Papers, Revista de Sociologia 100 (4): 395-423. http://dx.doi.org/10.5565/rev/papers.2223

Prades, J. 2015. La meditatització del conflicte ambiental: el cas de les Terres de l'Ebre. Tesis doctoral. Tarragona: Departamento de Estudios de Comunicación. Facultad de Letras, Universidad Rovira i Virgili.

Renn, O. 2008. Risk governance: coping with uncertainty in a complex world. London: Earthscan.

Riechmann, J. y F. Fernández Buey. 1994. Redes que dan libertad. Introducción a los nuevos movimientos sociales. Barcelona: Paidós.

Rubio-Varas, M. y J. de la Torre. 2016. "Spain - Eximbank'S Billion Dollar Client ": The Role Of The Us Financing The Spanish Nuclear Program". DT-AEHE 1603: 1-35.

Rubio-Varas, M., J. de la Torre, J. Espluga y A. Presas. 2017. "Spain: Short Country Report". Informe del proyecto History of Nuclear Energy and Society (HONEST, H2020) (en publicación). http://www.honest2020.eu/

Slovic, P. 1987. "Perception of Risk". Science 236 (4799): 280285. https://doi.org/10.1126/science.3563507

Slovic, P. 1993. "Perceived risk, trust, and democracy“. Risk analysis 13 (6): 675-682. https://doi. org/10.1111/j.1539-6924.1993.tb01329.x

Slovic, P. 1996. "Perception of risk from radiation". Radiation Protection Dosimetry 68 (3-4): 165-180. https://doi. org/10.1093/oxfordjournals.rpd.a031860

Solà Farré, R. (1999). La percepción del riesgo radiológico por público y expertos. Tesis doctoral. Madrid: Facultad de Psicología, Universidad Complutense.

Turner, G. y B. Wynne. 1992. "Risk communication: a literature review and some implications for biotechnology". Pp. 109-141 en Biotechnology in Public. A Review of Recent Research, editado por J. Durant. London: Science Museum for the European Federation of Biotechnology. 
Van Loon, J. 2000. "Virtual Risks in an Age of Cybernetic Reproduction". Pp. 165-182 in The Risk Society and Beyond, editado por B. Adam, U. Beck y J. Van Loon. London: Sage.

Visschers, V. H. y M. Siegrist. 2012. "Fair play in energy policy decisions: Procedural fairness, outcome fairness and acceptance of the decision to rebuild nuclear power plants". Energy Policy 46: 292-300. https://doi. org/10.1016/j.enpol.2012.03.062

Vlek, C., y P. J. Stallen. 1980. "Rational and Personal Aspects of Risk". Acta Psychologica 45: 273-300.
Walker, G., P. Simmons, B. Wynne y A. Irwin, A. 1998. Public perception of risks associated with major accident hazards. Sudbury: HSE Books.

Whitton, J., I. Parry, M. Cotton, W. Konrad, A. Prades López y J. Espluga. 2016. "Theoretical, Methodological and Epistemological Challenges of the Multi-disciplinary History of Nuclear Energy and Society (HoNESt) Research Project". Paper presented at ESSHC 2016, Valencia.

Wynne, B. 1996. "May the Sheep Safely Graze? A Reflexive View of the Expert-Lay Knowledge Divide". Pp. 44-83 en Risk, Environment and Modernity, editado por en S. Lash, B. Szerszynski and B. Wynne. London: Sage.

\section{Anexo. Documentación analizada para los casos}

\section{Caso 1: Vandellós I}

Cambra, L. 2003. "Enresa probará en Vandellòs I el desmantelamiento de la nuclear de Zorita". El País, 04/12/2003. (http://elpais.com/diario/2003/12/04/catalunya/1070503647_850215.html).

Ecologistas en Acción. 2014. El accidente de Vandellós I y las lecciones no aprendidas http://www.ecologistasenaccion.es/article25518.html

Fernández de Lis, P. 2005. "Cómo desmontar una central nuclear". El País, 28/08/2015. (http://elpais.com/diario/2005/08/28/sociedad/1125180005_850215.html).

Foro Nuclear. 2016. "The third Spanish nuclear power plant: Vandellós I". (http://www.foronuclear.org/es/askthe-expert/119884-the-third-spanish-nuclear-powerplant-vandellos-i).

Martínez, I. 2014. "La noche más larga de Vandellòs: 25 años del accidente nuclear". El Diario.es, 20/10/2014. (http://www.eldiario.es/catalunya/noche-larga-VandeIlos-accidente-nuclear_0_315669019.html).

Schnitzer, V. 1989. "La Agencia de Energía Atómica destaca que el suceso de Vandellòs se estima el más grave desde Chernobil". El País, 25/10/1989. (http://elpais.com/ diario/1989/10/25/espana/625273210_850215.html).

Terra-Ecología Práctica. 2014. "El accidente nuclear de Vandellós I, 25 años después". (http://www.terra.org/categorias/articulos/el-accidente-nuclear-de-vandellos-i25-anos-despues).

WISE. 1989. "Fire at Vandellos I" (https://www.wiseinternational.org/nuclear-monitor/320/fire-vandellos-i).

\section{Caso 2: Valdecaballeros}

Baigorri, A. 1999. "Del Estado depredador a la región sostenible. Efectos de la descentralización política y administrativa en el medio ambiente en España". Comunicación presentada en la Conference on The Environmental State Under Pressure: The Issues and the Research Agenda, 6-7, Agosto, Northwestern Uni- versity, Chicago. (http://www.insumisos.com/lecturasinsumisas/El \%20estado \%20depredador.pdf).

Canal Extremadura. 2015. "Central Nuclear de Valdecaballeros" (10/03/15). (http://www.canalextremadura.es/ alacarta/radio/audios/central-nuclear-de-valdecaballeros-100315).

Fernández, A. 2011. "El Gobierno se niega a desprenderse del terreno nuclear de Valdecaballeros". El Periódico de Extremadura, 30-01-2011. (http://www.elperiodicoextremadura.com/noticias/temadeldia/gobiernoniega-desprenderse-terreno-nuclear-valdecaballeros_558766.html).

Martínez, V. 2015. "El 'esqueleto nuclear' de los 2000 millones". El Mundo, 15/11/2015. (http://www.elmundo.es/econom ia/2015/11/15/5644de4c22601d80208b4614.html).

Munárriz, Á. 2008b. "Valdecaballeros duda de si valió la pena ser antinuclear". Público, 29-12-2008. (http://www.publico.es/actualidad/valdecaballeros-duda-valio-penaantinuclear.html).

Xaloc. 2008. "Nada ha vuelto a ser como antes". Público, 2912-2008. (http://www.publico.es/actualidad/vuelto.html).

\section{Caso 3: Almacén Temporal Centralizado}

Asociación de Empresas de Villar de Cañas. 2016. http://www. aevillardecañas.com/

Enresa. 2011. "El Almacén Temporal Centralizado". (http://www. enresa.es/esp/inicio/actividades-y-proyectos/atc).

Plataforma contra el Cementerio Nuclear en Cuenca. 2016. (http://cuencadicenoalcementerionuclear.blogspot. com.es/).

Plataforma Sí Queremos ATC en Villar de Cañas. 2016. (http:// plataformasiatc.blogspot.com.es/).

Prades, J. 2015. "La meditatització del conflicte ambiental: el cas de les Terres de l'Ebre". Tesis doctoral. Departamento de Estudios de Comunicación. Facultad de Letras, Universidad Rovira i Virgili, Tarragona. 
JOSEP ESPLUGA TRENC. Doctor en Sociología, profesor del Departamento de Sociología de la Universitat Autònoma de Barcelona, investigador del Instituto de Gobierno y Políticas Públicas (IGOP), especializado en sociología del riesgo, medio ambiente y salud. Es coordinador del Posgrado en Dinamización Local Agroecológica y del Minor en Desarrollo Sostenible y Ciudadanía Global de la UAB.

BEATRIZ MEDINA PARRA. Licenciada en Ciencias Ambientales, investigadora del Instituto de Gobierno y Políticas Públicas (IGOP). Máster en Comunicación Científica (UPF). Está especializada en el análisis de riesgos ambientales y la gestión de la comunicación ambiental. Ha trabajado en numerosos proyectos europeos sobre estos temas como investigadora en WE\&B y en el CIEMAT.

ALBERT PRESAS. Doctor en Historia por la Technische Universität Berlin, profesor del Departamento de Humanidades de la Universitat Pompeu Fabra, y profesor visitante en el Instituto Planck para la Historia de la Ciencia en Berlín. Sus intereses de investigación se centran en la ciencia, la cultura y el poder; ciencia en la periferia europea; ciencia y franquismo y la historia de la energía nuclear.

MAR RUBIO-VARAS. Doctora en Economía por la London School of Economics (Reino Unido). Profesora del Departamento de Economía de la Universidad Pública de Navarra. Es economista de la energía e historiadora económica. Sus intereses de investigación se centran en las relaciones a largo plazo entre la energía, consumo y crecimiento económico, cubriendo también aspectos de la dependencia externa energética y la transición a una economía baja en carbono. Recientemente se ha centrado en los aspectos económicos y financieros de la historia y desarrollo del programa nuclear español.

JOSEBA DE LA TORRE. Doctor en Historia y profesor de Historia Económica del Departamento de Economía. Universidad Pública de Navarra. Su actual campo de investigación principal es la política económica española durante el franquismo y, en particular, la política industrial y la planificación del desarrollo (décadas de 1940 a 1970). Ha sido profesor visitante en La Maison des Sciences de l'Homme en París (FR) y en el Centro de Estudios Europeos y Mediterráneos de la New York University. Junto a la Dra. Rubio-Varas dirige un equipo de investigación para el estudio sobre la historia económica de la energía nuclear en España. 